\title{
Enhanced Safety Surveillance of Seasonal Quadrivalent Influenza Vaccines in English Primary Care: Interim Analysis
}

\author{
Simon de Lusignan (D) - Gaël Dos Santos · Rachel Byford · \\ Anne Schuind - Silvia Damaso • Vishvesh Shende $\cdot$ Chris McGee • \\ Ivelina Yonova $\cdot$ Filipa Ferreira
}

Received: May 22, 2018 / Published online: July 11, 2018

(C) The Author(s) 2018

\section{ABSTRACT}

Introduction: The European Medicines Agency (EMA) requires vaccine manufacturers to conduct enhanced safety surveillance (ESS) of seasonal influenza vaccines including a near real-

Enhanced digital features To view enhanced digital features for this article go to https://doi.org/10.6084/ m9.figshare.6652805.

Electronic supplementary material The online version of this article (https://doi.org/10.1007/s12325018-0747-4) contains supplementary material, which is available to authorized users.

S. de Lusignan $(\bowtie) \cdot$ R. Byford · C. McGee .

I. Yonova · F. Ferreira

Department of Clinical and Experimental Medicine,

University of Surrey, Surrey, UK

e-mail: s.lusignan@surrey.ac.uk

G. Dos Santos · S. Damaso

GlaxoSmithKline, Wavre, Belgium

\section{A. Schuind}

Vaccine Discovery and Clinical Research and

Development, GlaxoSmithKline, Rockville, MD, USA

\section{Shende}

Vaccines Clinical Safety and Pharmacovigilance Department, VPN Consultancy Ltd (on behalf of GSK), London, UK

\section{McGee · I. Yonova}

Department of Clinical and Experimental Medicine, Royal College of General Practitioners, London, UK time evaluation of collected data. The objective was to identify whether the use of passive surveillance or active surveillance provides different results of reported adverse events of interest (AEIs) by specified age strata and AEI type. We report the weekly incidence rates of AEIs within 7 days following seasonal influenza vaccination using passive and active surveillance.

Methods: AEIs were collected within 7 days of vaccination from ten general practices predominantly administering inactivated quadrivalent influenza vaccine (IIV4, Fluarix Tetra, GSK). Vaccinees completed an adverse drug reaction (ADR) card. ADR card and medically attended AEIs data were recorded in practice electronic health records. We report the outcome of the first 5 weeks of safety surveillance (September 12, 2016-October 16, 2016); in an exploratory analysis, rates of AEI for IIV4 are compared to those passively reported through a sentinel network.

Results: Practices vaccinated $13.1 \%(12,864 /$ $98,091)$ of their registered population; $5.6 \%$ (95\% CI 5.20-6.00) of them reported AEIs, none serious. The most frequent were respiratory $2.60 \% \quad(95 \%$ CI $2.33-2.88)$, musculoskeletal $1.82 \%(95 \%$ CI $1.59-2.05)$ and neurological $1.05 \%$ (95\% CI $0.88-1.23$ ). AEIs were more frequently reported for adults than for children; $5.91 \%$ (95\% CI 5.49-6.34) compared to $1.49 \%$ (95\% CI $0.69-2.29) ; 47.18 \%$ of the adults reported AEI using the ADR card, none were 
returned for subjects $<18$ years old. The frequency of AEIs reporting was higher, $6.88 \%$ $(95 \%$ CI $6.35-7.42) \quad$ vs. $3.30 \% \quad(95 \% \quad$ CI $2.68-3.96,100 / 3028, p<0.000)$, through ESS than passive surveillance.

Conclusion: The ESS did not reveal any safety signal and we demonstrated the feasibility of conducting ESS following EMA recommendations. The use of a customised ADR card led to a doubling of AEIs reports over passive surveillance in adults.

Funding: GlaxoSmithKline Biologicals SA, Wavre, Belgium.

Keywords: Adverse events; Adverse reaction reporting systems; Evaluation studies as a topic; General practice; Immunology; Infectious diseases; Influenza; Medical record systems, computerized; Vaccination

\section{INTRODUCTION}

\section{Background}

\section{European Medicine Agency (EMA) Guidance on Influenza Vaccines}

The EMA set out new standards for Marketing Authorisation Holders who produce influenza vaccines for use within the EU. An interim guideline was released in August 2014 and further updated in July 2016 and came into effect in February $2017[1,2]$.

These news standards set out a requirement for safety and reactogenicity monitoring of seasonal influenza vaccines with a new strain composition. These vaccines are to be evaluated for local (at the injection site) and systemic (e.g. fever, myalgia) adverse events of interest (AEI) in specified age groups, with timely relevant findings to be provided to the competent regulatory authorities.

The previous requirement to conduct smallscale safety and immunogenicity clinical trials was withdrawn in 2015 [3]. The rationale for this change was that these trials had insufficient power to adequately evaluate safety of annual formulation changes because of the relatively low frequency of some adverse events [4-7]. The trials were to be replaced by enhanced safety surveillance and post-marketing monitoring program, and vaccine effectiveness assessments.

\section{The EMA Guidance Set Out Three Options Envisioned for Enhanced Surveillance}

- Enhanced active surveillance [post authorisation safety studies (PASS)]: The PASS should follow up defined cohorts of adults and children using web-based reporting or diary cards for 7 days [or 14 for live attenuated influenza vaccine (LAIV)] after immunisation. The PASS should include specific endpoints of AEIs.

- Enhanced passive surveillance: The principle is to rapidly monitor vaccine usage and to facilitate rapid adverse drug reaction (ADR) reporting.

- Data mining or other use of electronic health record (EHR).

\section{English Primary Care as a Setting for Enhanced Safety Surveillance}

Primary care in England has a registration-based list system that has been highly computerised since 2004 and data extracted from this system are widely used in research $[8,9]$. Key data are recorded in EHRs using the Read coding system, a detailed classification system able to record the EMA-specified AEIs [10]. General practices are largely independent professional partnerships and make their own decision about which brand of influenza vaccines to purchase prior to the start of the influenza season; they generally follow the Chief Medical Officer's recommendation (Fig. 1) by giving inactivated influenza vaccine (IIV) to most adults and LAIV [11] to children.

In the 2015-2016 influenza season, we demonstrated the feasibility of conducting enhanced passive surveillance to address EMA guidelines on seasonal influenza vaccines using routinely collected primary care data [12]. The methods used for data extraction and processing were those developed by the University of Surrey to support the Royal College of General Practitioners (RCGP) Research and Surveillance Centre (RSC) [13]. 
- People aged 65 years or over (based on age on 31 March 2017)

- People aged from 6 months to less than 65 years of age with a serious medical condition such as:

- chronic (long-term) respiratory disease, such as severe asthma,

- chronic obstructive pulmonary disease (COPD) or bronchitis

- chronic heart disease, such as heart failure

- chronic kidney disease at stage three, four or five

- chronic liver disease

- chronic neurological disease, such as Parkinson's disease or motor neurone disease, or learning disability

- diabetes

- splenic dysfunction

- immunocompromised due to disease (e.g. HIV/AIDS) or treatment (e.g. cancer treatment)

- All pregnant women (including those women who become pregnant during the flu season)

- All those aged two, three, and four years (but not five years or older) on 31 August 2016 (i.e., date of birth on or after 1 September 2011 and on or before 31 August 2014) through general practice

- All children of school years 1, 2 and 3 age through locally commissioned arrangements

- Primary school-aged children in areas that participated in primary school pilots since $2014 / 15^{1}$

- People living in long-stay residential care homes or other long-stay care facilities

- People who are in receipt of a carer's allowance, or those who are the main carer of an older or disabled person.

- Household contacts of immunocompromised individuals.

Fig. 1 UK Chief Medical Officer's recommendations for influenza vaccination [36]

In the 2016-2017 season, passive surveillance was enhanced by the use of a customised ADR card distributed to patients vaccinated with GlaxoSmithKline's (GSK) Fluarix Tetra in the ten GP practices. We designed an "orange card" which included a structured list of EMAspecified AEIs, which we grouped into body systems, as well as the option for study participants to report that no AEI or any other adverse events (AEs) occurred post vaccination (see Sect. "The Orange Card"). Our method builds on the study we conducted in 2015-2016 [14], whilst improving the usability of the orange card.

\section{Challenges for Pharmacovigilance}

Seasonal influenza vaccination presents challenges for pharmacovigilance. These include yearly immunisation in large population cohorts in a relatively short time period, and multiplicity of vaccine products on the market with the need to conduct product-specific safety surveillance and report findings in a near realtime manner. The 2016/2017 influenza plan recommended the vaccination of high-risk groups and children, who are likely to be the vectors of influenza virus transmission (Fig. 1) [15]. Healthcare practitioners are also able to apply medical judgement and recommend vaccination as prevention of exacerbation of underlying diseases. General practices in England usually start administering influenza vaccines in September each year [16]; in parallel a smaller number of vaccinations are administered at school or community pharmacies [17].

In addition to the large number of people being vaccinated and therefore at risk of minor AEIs, influenza vaccinations have previously been associated with developing Guillain-Barré syndrome [18] and narcolepsy [19]. Therefore, with the large amount of people being vaccinated in such a short period of time, and the potential for developing severe AEIs, fast and reliable reporting of AEIs is important.

This study was conducted to address the EMA requirements. Here we present interim results of enhanced passive surveillance and enhanced active surveillance (passive 
surveillance plus the orange card), between September 12, 2016 and October 16, 2016 (International Standards Organisation (ISO) weeks 37-41).

\section{Objective}

The objective was to identify whether the use of passive surveillance or active surveillance provides different results of reported AEI by specified age strata and AEI type. We report the weekly incidence rates of AEIs within 7 days following seasonal influenza vaccination using passive and active surveillance.

\section{METHODS}

\section{Study Design}

We defined active surveillance practices as the ten practices who predominantly used GSK influenza vaccinations during the interim period of September to October 2016. Patients from these practices were invited to record adverse events within 7 days post-vaccination and were asked to return the card to their registered practice no later than 14 days post-vaccination. Any AEI derived from the orange cards was entered into the practice EHR, whereas cards returned showing no report of ADR were retained by the practice and counted.

We operationalised enhanced passive surveillance in two ways. Firstly, through the ten practices who used the orange cards, but by looking at AEIs reported and extracted from the practices' EHRs rather than the orange cards. Secondly, by comparing adverse events reported by all other practices from a sentinel network (Royal College of General Practitioners Research and Surveillance Centre; RCGP RSC) in England, who used GSK vaccinations.

This study builds on the key learnings and gaps of an initial pilot study in England in 2015 and continuous feedback received from the Pharmacovigilance Risk Assessment Committee (PRAC) of the EMA and the Vaccine Working Party (safety task force). We did not register this study as a clinical trial as the intervention was not used to treat patients, but rather to see if it increased surveillance of AEIs.

\section{Setting}

Ten volunteer general practices who stated that GSK's Fluarix Tetra would be the main brand of influenza vaccine for the 2016/2017 season participated in the study. We enrolled practices spread across England: three practices each in North, Midlands and East, and South NHS Regions, with the tenth practice in London. The practices used different EHR systems. Practices' reimbursement followed National Institute of Health Research (NIHR) guidelines for industrysponsored studies.

\section{Participants}

\section{Inclusion Criteria}

All patients receiving a seasonal influenza vaccine between September 1, 2016 and November 30, 2016 in participating practices were eligible for inclusion in the study. The period for this interim report is September 12, 2016 to October 16, 2016, International Standards Organisation (ISO) weeks 37-41.

\section{Exclusion Criteria}

Patients who had explicitly opted out of data sharing were excluded. According to a National Health Service (NHS) communication, it is estimated that around $1.25 \%$ of the population has opted out (patients registered an objection to their identifiable information) [20]. Patients without a valid NHS number (which we pseudonymise to link data) or gender recorded in the EHR were excluded.

\section{Variables}

We defined exposure to seasonal influenza vaccine as a coded EHR record of either a vaccination administration code, a vaccine prescription or both.

We created lists of Read codes [21] for the AEIs specified by EMA, using an ontological 
approach grouping conditions by categories as follows $[22,23]$.

- Respiratory: conjunctivitis, coryza, cough, epistaxis, hoarseness, nasal congestion, oropharyngeal pain, rhinorrhoea, wheezing

- Musculoskeletal: arthropathy, muscle aches/ myalgia

- Neurological: Bell's palsy, Guillain-Barré syndrome (GBS), headache, peripheral tremor, seizure/febrile convulsions

- General symptoms: drowsiness, fatigue, irritability, malaise

- Gastrointestinal: decreased appetite, diarrhoea, nausea, vomiting

- Local symptoms: local erythema

- Fever/pyrexia: fever, including actual temperatures recorded, when available

- Rash: generalised rash, or other distribution

- Sensitivity/anaphylaxis: anaphylactic reactions, facial oedema, hypersensitivity reactions

All the clinical codes used: Read codes version 2 and Read Clinical Terms version 3 for the AEI's are presented in the Electronic Supplementary Material 1.

\section{The Orange Card}

The orange card was a strategy implemented to improve reporting of AEIs after vaccinations. One of the issues with passive surveillance is that not everybody will report to practice with an AEI. The orange card aims to overcome this issue by asking patients to report if they have had an AEI (no matter how minor) and return the card back to the practice. This is a clear advantage of using orange cards over passive surveillance. Patients are asked to provide demographic details, vaccine details, and whether or not they had any AEIs. If participants had any AEIs they were required to fill out tick boxes indicating the symptom (written in plain English), the severity, and whether the symptom was still present.

\section{Compliance with Ethics Guidelines}

Ethics committee approval was obtained in England from the Health Research Authority
(IRAS project ID 211560). GlaxoSmithKline Biologicals SA, Wavre, Belgium funded the project and was involved in study design and interpretation. This study received a favourable ethics committee approval: Integrated Research Application System (IRAS) project ID 211560; Research Ethics Committee (REC) reference 16/NE/0271. All procedures performed in studies involving human participants were in accordance with the ethical standards of the institutional and/or national research committee and with the 1964 Helsinki declaration and its later amendments or comparable ethical standards. Informed consent was obtained from all individual participants included in the study.

\section{Data Sources/Measurement}

We extracted the data on a weekly basis using an automated extraction protocol and produced weekly reports of the incidence of AEIs by the variable grouping shown above; an issue of the weekly report is presented in the Electronic Supplementary Material 2.

\section{Bias}

It is likely that conditions that do not require medical attendance may have been underreported, such as local reactions or minor systemic symptoms. We tried to overcome this limitation by asking vaccinated patients to return the cards even if they did not experience any $\mathrm{AE}$, reporting that no AEI occurred. However, we made no provision for recording returned negative cards.

\section{Sample Size}

We recruited ten volunteer practices whose combined list size exceeded the required sample size intended in our protocol. Using conservative assumptions, we estimated that approximately 70,000 registered patients would be required to enrol sufficient number of vaccinees $(n=5000)$. As mean practice size in England and Wales was 7034, we recruited ten practices. We assumed that vaccination uptake in the 
$2016 / 2017$ season would be similar to the previous one where $71.0 \%$ of subjects over 65 years, $45.1 \%$ of those in a clinical risk group aged 6 months to 65 years and $42.3 \%$ of pregnant women were vaccinated [24]. With comparable vaccination uptake, at the time of the protocol development, we expected to enrol at least 5000 vaccinees, allowing a study sufficiently powered to detect most of common AEs regardless of the expected probability of occurrence. The scenarios and assumptions are described in depth previously as part of the learning from our first study [16]. Participating practices had larger list sizes than the national average resulting in a total of 98,091 registered patients at the start of the study (ISO week 37).

\section{Quantitative variables}

We included one quantitative variable, temperature recording. This variable was cleaned, as per our standard practice [25], correcting likely data entry errors, such as missing decimal points or recording in Fahrenheit.

\section{Comparator Data}

In the absence of well-defined comparator we compared the data extracted in this study with a passive surveillance system, i.e. without the enhancement of ADR cards [17]. We used a data extract for the same dates from the RCGP RSC, extracting data for people only given GSK Fluarix Tetra ${ }^{\mathrm{TM}}$ brand vaccine. This extract reported rates of AEI in people who had received any brand flu vaccine. The RCGP RSC has over 50 years involvement in influenza monitoring and vaccine effectiveness studies [26]. Practices have a dashboard [27] and receive feedback to improve data quality [28].

\section{Statistical Methods}

The rates of AEIs were computed overall, for each AEI and by category of AEI. We used the number of registered patients vaccinated with a GSK vaccination in weeks $37-41$ as the denominator, and AEIs reported within 7 days after vaccination reported in EHR or through the orange card as the numerator; patients may have reported more than one AEI. We report the rates and percentages of patients vaccinated in weeks 37-41 with the GSK vaccination, and with any non-GSK vaccination for comparison (Table 1). We then report AEIs from the ten orange card practices for reported AEIs using the orange cards, and AEIs using any method. We carry out a chi-square test to see if there are statistically significant age differences in orange card reporting between groups or practices (Tables 2,3 ). In the weekly report, the denominators are patients vaccinated in the reported week and the preceding week as reporting an AEI can straddle 2 weeks. We report 95\% confidence intervals $(95 \% \mathrm{CI})$ on AEI rates, using the critical binomial function in Microsoft Excel [29] (Tables 4, 6). We then compared the

Table 1 Vaccination by age groups for GSK and non-GSK vaccinations (weeks 33-41, $n=12,864$ )

\begin{tabular}{|c|c|c|c|c|c|c|}
\hline \multirow[t]{2}{*}{ Age band } & \multicolumn{3}{|c|}{ GSK vaccinations } & \multicolumn{3}{|c|}{ Non-GSK vaccinations } \\
\hline & $\begin{array}{l}\text { Number of } \\
\text { vaccinated } \\
\text { patients (weeks } \\
33-41 \text { ) }\end{array}$ & $\begin{array}{l}\% \text { of GSK } \\
\text { vaccinated } \\
\text { patients }\end{array}$ & $\begin{array}{l}\% \text { of all } \\
\text { patients } \\
\text { vaccinated } \\
\text { with GSK }\end{array}$ & $\begin{array}{l}\text { Number of } \\
\text { vaccinated } \\
\text { patients (weeks } \\
33-41 \text { ) }\end{array}$ & $\begin{array}{l}\% \text { of non- } \\
\text { GSK } \\
\text { vaccinated } \\
\text { patients }\end{array}$ & $\begin{array}{l}\% \text { of all } \\
\text { patients } \\
\text { vaccinated with } \\
\text { non-GSK }\end{array}$ \\
\hline 6 months -5 years & 6 & 0.07 & 0.05 & 559 & 13.16 & 4.35 \\
\hline $6-12$ years & 12 & 0.14 & 0.09 & 226 & 5.32 & 1.76 \\
\hline $13-17$ years & 32 & 0.37 & 0.25 & 40 & 0.94 & 0.31 \\
\hline $18-65$ years & 2690 & 31.22 & 20.91 & 1308 & 30.78 & 10.17 \\
\hline Over 65 years & 5875 & 68.20 & 45.67 & 2116 & 49.80 & 16.44 \\
\hline Total & 8615 & 100 & 66.97 & 4249 & 100 & 33.03 \\
\hline
\end{tabular}

GSK GlaxoSmithKline plc 
Table 2 Summary of AEIs reported using the ADR orange card or any method for GSK vaccines, by age band (weeks $37-41)$

\begin{tabular}{lccl}
\hline Age band & $\begin{array}{l}\text { Patients with an AEI reported by } \\
\text { any method within 7 days of } \\
\text { vaccination (weeks 37-41) }\end{array}$ & $\begin{array}{l}\text { Patients with an AEI reported by } \\
\text { orange card within 7 days of } \\
\text { vaccination (weeks 37-41) }\end{array}$ & $\begin{array}{l}\text { \% of patients reporting } \\
\text { AEIs using an orange } \\
\text { card (95\% CI) }\end{array}$ \\
\hline 6 months-5 years & 9 & 0 & 0.00 \\
6-12 years & 4 & 0 & 0.00 \\
13-17 years & 0 & 0 & 0.00 \\
Children total & 13 & 0 & 0.00 \\
18-65 years & 256 & 118 & $46.09(39.84-52.34)$ \\
$>$ 65 years & 452 & 216 & $47.79(43.14-52.43)$ \\
Adults total & 708 & 334 & 47.18 \\
All ages (over & 721 & 334 & 46.32 \\
6 months) & & & \\
\hline
\end{tabular}

AEIs adverse events of interest

proportion of people administered GSK's Fluarix Tetra (only) who reported an AEI in the study with those reported for the same brand of vaccine across the RCGP RSC using 95\% CI and Pearson chi-square test. We report crude AEI rates but also compare age-standardised rates using the 2015 census population [30] (Table 7).

The cluster effect of general practices has not been taken into account in the present interim analysis nor in the previous year's study. Importantly, accounting for the cluster effect may increase the relative standard error, leading to wider confidence intervals around the estimated rates; hence, it should be accounted for in the final analysis [31].

\section{Ethical Considerations}

This study received a favourable ethics committee approval: Integrated Research Application System (IRAS) project ID: 211560; Research Ethics Committee (REC) reference: 16/NE/0271.

\section{RESULTS}

\section{Seasonal Influenza Vaccination Exposure}

Most general practices influenza vaccination began in ISO week 37 (starting 12/09/16);
Table 4 Rate of AEIs recorded in vaccinated patients (all reporting methods) for GSK vaccines, weeks 37-41

\begin{tabular}{llcl}
\hline $\begin{array}{l}\text { ISO } \\
\text { week }\end{array}$ & $\begin{array}{l}\text { Patients with } \\
\text { AEIs reported } \\
\text { 7 days post- } \\
\text { vaccination }\end{array}$ & $\begin{array}{l}\text { Vaccinated } \\
\text { patients }\end{array}$ & $\begin{array}{l}\text { Rate }(\mathbf{9 5 \%} \text { CI) } \\
(\%)\end{array}$ \\
\hline $37^{\mathrm{a}}$ & 58 & 1927 & $3.01(2.28-3.79)$ \\
38 & 157 & 3166 & $4.96(4.20-5.72)$ \\
39 & 192 & 2751 & $6.98(6.03-7.96)$ \\
40 & 165 & 3162 & $5.22(4.46-6.01)$ \\
41 & 149 & 1849 & $8.06(6.91-9.30)$ \\
Total & 721 & 12,855 & $5.61(5.21-6.01)$ \\
\hline
\end{tabular}

AEIs adverse events of interest

${ }^{a} 91$ of these vaccines were administered in week 37 and given AEI cards ahead of the start of the study

however, $0.01 \%(n=9)$ of patients were vaccinated prior to this, between weeks 33 and 36 . All patients receiving a seasonal influenza vaccine between weeks 37 (September 12, 2016) and 41 (October 16, 2016) in participating practices were eligible for inclusion in the analysis $(n=12,855)$. Practices had vaccinated $13.1 \%(12,864 / 98,091)$ of their registered 
Table 3 Summary of AEIs reported using the ADR orange card or any method for GSK vaccines, by practice (weeks 37-41)

\begin{tabular}{ccclll}
\hline Practice & $\begin{array}{l}\text { Practice } \\
\text { denominator }\end{array}$ & $\begin{array}{l}\text { Number of } \\
\text { GSK } \\
\text { vaccinations }\end{array}$ & $\begin{array}{l}\text { Patients with an AEI } \\
\text { reported by any method } \\
\text { within 7 days of } \\
\text { vaccination (weeks 37-41) }\end{array}$ & $\begin{array}{l}\text { Patients with an AEI } \\
\text { reported by orange card } \\
\text { within 7 days of } \\
\text { vaccination (weeks 37-41) }\end{array}$ & $\begin{array}{l}\text { \% of AEIs } \\
\text { reported using an } \\
\text { ADR card } \\
\text { (95\%CI) }\end{array}$ \\
\hline Practice 1 & 5769 & 740 & 78 & 54 & $69.2(58.97-79.49)$ \\
Practice 2 & 4736 & 629 & 57 & 26 & $45.6(33.33-57.89)$ \\
Practice 3 & 10,126 & 0 & 56 & 4 & $7.1(1.79-14.29)$ \\
Practice 4 & 7383 & 881 & 41 & 19 & $46.3(31.71-60.98)$ \\
Practice 5 & 11,683 & 9 & 16 & 4 & $25.0(6.25-50.00)$ \\
Practice 6 & 14,689 & 2015 & 108 & 79 & $73.1(64.81-81.48)$ \\
Practice 7 & 16,852 & 437 & 78 & 31 & $39.7(29.49-51.28)$ \\
Practice 8 & 9531 & 1135 & 66 & 32 & $48.5(36.36-60.61)$ \\
Practice 9 & 9526 & 1103 & 94 & 65 & $69.1(59.57-78.72)$ \\
Practice & 10,391 & 1666 & 127 & 20 & $15.7(9.45-22.05)$ \\
10 & & & & & \\
\hline
\end{tabular}

population by week 41 , including the vaccinees prior to week 37 (Table 1).

The highest rate of seasonal influenza vaccination uptake was reported in subjects over 65 years of age with more than half $(62.12 \%)$ vaccinated by week 41 (Table 1 ). Across recruited practices most adult vaccination was with GSK brand vaccine, whereas in children under 13 years most were vaccinated with non-GSK vaccine. Most are likely to have been given LAIV as per UK recommendations, with only those with chronic conditions given the GSK vaccine.

\section{Return Rate of Orange Cards and Use in Reporting AEIs}

A total of 334 cards were returned with AEIs recorded during weeks $37-41$. Of adult patients ( $\geq 18$ years old) reporting an AEI, $47.2 \%$ did so via the orange card method. The percentage of patients reporting AEIs using orange card was similar between $18-65$ years and above 65 years of age; $46.1 \%$ and $47.8 \%$ respectively. There were no significant differences in the ages of those reporting AEIs via the orange card $(p=0.66)$ (Table 2).

There were significant differences in the number of practices recording AEIs using the orange cards $(p<0.001)$. Looking at the denominator and number of patients vaccinated with GSK vaccine, no clear pattern emerges (Table 3). Whilst it was intended that cards were exclusively distributed to patients receiving the GSK vaccine over the study period, five orange cards were returned reporting AEIs from vaccinees who did not receive GSK vaccine. We believe this was likely due to human error.

\section{Total Reporting of AEIs}

We report AEIs from both routine visit and ADR card, for GSK vaccines. The overall rate of AEIs reported was $5.61 \% \quad(95 \%$ CI $5.21-6.01)$, although this varied from $3.01 \%$ to $8.06 \%$ between weeks (Table 4). There were 943 reports of AEIs in 721 individual patients.

Adults reported more AEIs than were reported by children or on their behalf; $5.9 \%$ (95\% CI 
Table 5 Rate of AEIs recorded in vaccinated patients (all reporting methods) for GSK vaccines, by age band (weeks 37-41)

\begin{tabular}{lccc}
\hline Age band & $\begin{array}{l}\text { Patients with AEIs reported 7 days post- } \\
\text { vaccination }\end{array}$ & $\begin{array}{l}\text { Vaccinated } \\
\text { patients }\end{array}$ & $\begin{array}{l}\text { Rate }(\mathbf{9 5 \%} \mathbf{C I}) \\
(\%)\end{array}$ \\
\hline 6 months-5 years & 9 & 565 & $1.59(0.71-2.65)$ \\
$6-12$ years & 4 & 238 & $1.68(0.42-3.36)$ \\
$13-17$ years & 0 & 72 & $0.0(\mathrm{~N} / \mathrm{A})$ \\
Total children & 13 & 875 & $1.49(0.69-2.29)$ \\
$18-65$ years & 256 & 3992 & $6.41(5.66-7.19)$ \\
$>$ 65 years & 452 & 7988 & $5.66(5.16-6.17)$ \\
Total adults & 708 & 11,980 & $5.91(5.49-6.34)$ \\
All ages (over & 721 & 12,855 & $5.61(5.21-6.01)$ \\
$\quad 6$ months) & & & \\
\hline
\end{tabular}

$A E I s$ adverse events of interest

5.5-6.3) compared to $1.5 \%(95 \%$ CI $0.7-2.3)$ (Table 5).

A wide range of possible AEIs were reported, none were serious. Respiratory, musculoskeletal and neurological were the most common type of AEI reported using our ontological classification. Respiratory were the most frequent, $2.60 \%$ (95\% CI 2.33-2.88), then musculoskeletal $1.82 \%$ (95\% CI 1.59-2.05), then neurological $1.05 \%$ (95\% CI 0.88-1.23). For full details, see Table 6. No serious adverse events (SAEs) such as Bell's palsy, Guillain-Barré syndrome or anaphylaxis were reported to the participating GP.

For patients coded as having a fever or who had their temperature recorded $(n=57)$, in $91 \%$ of cases a valid numerical value was recorded. Most temperatures were recorded as tympanic measurements and near to normal, median $37^{\circ} \mathrm{C}$ (interquartile range 0.5 ).

\section{Comparison with Contemporaneous RCGP RSC Surveillance Network Data}

No formal comparison was performed between the data collected from the ten GPs and the RCGP RSC surveillance network. Nevertheless, this evaluation provides insight into the added value of the enhanced methodology.

The overall rates of AEIs for those vaccinated with GSK vaccine in this study were higher than that reported by the rest of the RCGP RSC for the same weeks $6.88 \%$ (95\% CI $6.35-7.42$, $593 / 8615)$ vs. $3.30 \% \quad(95 \%$ CI $2.68-3.96$, $100 / 3028, p<0.0001)$, respectively. All but two of the AEI categories were reported more frequently in the study practices using ADR cards than in the passive surveillance RCGP RSC practices (Table 7). Age-standardised rates were 7.41\% (95\% CI 4.97-12.74) and 2.62\% (95\% CI 1.98-4.05), respectively, for study and RCGP RSC practices.

\section{DISCUSSION}

\section{Key Results}

This report shows that it is possible to collect data on AEIs occurring within the 7 days post vaccination in near real time from GP EHR systems. The ADR card system was used by adults and led to a doubling of reported events compared to passive surveillance. In adults, the rate of reported AEIs was consistent across age groups, with $46 \%$ of patients reporting AEI by means of an ADR card. The other half were recorded as part of standard healthcare. There was no difference between the working age and retired age in the rate of AEI reporting via orange cards; however, a lower proportion was 
Table 6 Rate of AEI reported from all sources for GSK vaccines by clinical category (weeks 37-41)

\begin{tabular}{|c|c|c|c|c|}
\hline AEI category & $\begin{array}{l}\text { EMA surveillance } \\
\text { condition }\end{array}$ & $\begin{array}{l}\text { Instances of AEIs for } \\
\text { GSK vaccines }\end{array}$ & $\begin{array}{l}\text { Denominator for GSK } \\
\text { vaccine practices }\end{array}$ & Rate (\%) \\
\hline All & & 721 & 12,855 & $5.61(5.21-6.01)$ \\
\hline \multirow[t]{10}{*}{ Respiratory } & Conjunctivitis & 23 & 12,855 & $0.18(0.11-0.26)$ \\
\hline & Coryza & 57 & 12,855 & $0.44(0.33-0.56)$ \\
\hline & Cough & 136 & 12,855 & $1.06(0.89-1.24)$ \\
\hline & Epistaxis & 9 & 12,855 & $0.07(0.03-0.12)$ \\
\hline & Hoarseness & 42 & 12,855 & $0.33(0.23-0.43)$ \\
\hline & Nasal congestion & 180 & 12,855 & $1.40(1.20-1.61)$ \\
\hline & Oropharyngeal pain & 82 & 12,855 & $0.64(0.51-0.78)$ \\
\hline & Rhinorrhoea & 149 & 12,855 & $1.16(0.98-1.35)$ \\
\hline & Wheezing & 40 & 12,855 & $0.31(0.22-0.41)$ \\
\hline & Subtotal & 334 & 12,855 & $2.60(2.33-2.88)$ \\
\hline \multirow[t]{3}{*}{ Musculoskeletal } & Arthropathy & 53 & 12,855 & $0.41(0.30-0.53)$ \\
\hline & Muscle aches/myalgia & 222 & 12,855 & $1.73(1.51-1.95)$ \\
\hline & Subtotal & 234 & 12,855 & $1.82(1.59-2.05)$ \\
\hline \multirow[t]{6}{*}{ Neurological } & Headache & 130 & 12,855 & $1.01(0.84-1.19)$ \\
\hline & Peripheral tremor & 17 & 12,855 & $0.13(0.07-0.20)$ \\
\hline & Bell's palsy & 0 & 12,855 & $0.00(\mathrm{~N} / \mathrm{A})$ \\
\hline & $\begin{array}{c}\text { Guillain-Barré } \\
\text { syndrome }\end{array}$ & 0 & 12,855 & $0.00(\mathrm{~N} / \mathrm{A})$ \\
\hline & $\begin{array}{c}\text { Seizure/febrile } \\
\text { convulsions }\end{array}$ & 0 & 12,855 & $0.00(\mathrm{~N} / \mathrm{A})$ \\
\hline & Subtotal & 135 & 12,855 & $1.05(0.88-1.23)$ \\
\hline \multirow{5}{*}{$\begin{array}{l}\text { General } \\
\text { symptoms }\end{array}$} & Drowsiness & 41 & 12,855 & $0.32(0.23-0.42)$ \\
\hline & Fatigue & 102 & 12,855 & $0.79(0.65-0.95)$ \\
\hline & Irritability & 13 & 12,855 & $0.10(0.05-0.16)$ \\
\hline & Malaise & 3 & 12,855 & $0.02(0.00-0.05)$ \\
\hline & Subtotal & 126 & 12,855 & $0.98(0.82-1.15)$ \\
\hline \multirow[t]{5}{*}{ Gastrointestinal } & Decreased appetite & 34 & 12,855 & $0.26(0.18-0.36)$ \\
\hline & Diarrhoea & 36 & 12,855 & $0.28(0.19-0.37)$ \\
\hline & Nausea & 47 & 12,855 & $0.37(0.26-0.47)$ \\
\hline & Vomiting & 14 & 12,855 & $0.11(0.05-0.17)$ \\
\hline & Subtotal & 101 & 12,855 & $0.79(0.64-0.94)$ \\
\hline
\end{tabular}


Table 6 continued

\begin{tabular}{|c|c|c|c|c|}
\hline AEI category & $\begin{array}{l}\text { EMA surveillance } \\
\text { condition }\end{array}$ & $\begin{array}{l}\text { Instances of AEIs for } \\
\text { GSK vaccines }\end{array}$ & $\begin{array}{l}\text { Denominator for GSK } \\
\text { vaccine practices }\end{array}$ & Rate (\%) \\
\hline \multirow[t]{2}{*}{ Local symptoms } & Local erythema & 75 & 12,855 & $0.58(0.46-0.72)$ \\
\hline & Subtotal & 75 & 12,855 & $0.58(0.46-0.72)$ \\
\hline \multirow[t]{3}{*}{ Fever/pyrexia } & $\begin{array}{l}\text { Fever (no numeric } \\
\text { value) }\end{array}$ & 28 & 12,855 & $0.22(0.14-0.30)$ \\
\hline & $\begin{array}{l}\text { Fever (value } \\
\text { recorded) }\end{array}$ & 57 & 12,855 & $0.44(0.33-0.56)$ \\
\hline & Subtotal & 85 & 12,855 & $0.66(0.52-0.80)$ \\
\hline \multirow[t]{3}{*}{ Rash } & Generalised rash & 27 & 12,855 & $0.21(0.13-0.30)$ \\
\hline & Rash & 8 & 12,855 & $0.06(0.02-0.11)$ \\
\hline & Subtotal & 35 & 12,855 & $0.27(0.19-0.37)$ \\
\hline \multirow{4}{*}{$\begin{array}{l}\text { Sensitivity/ } \\
\text { anaphylaxis }\end{array}$} & Facial oedema & 1 & 12,855 & $0.01(0.00-0.02)$ \\
\hline & $\begin{array}{l}\text { Anaphylactic } \\
\text { reactions }\end{array}$ & 0 & 12,855 & $0.00(\mathrm{~N} / \mathrm{A})$ \\
\hline & $\begin{array}{l}\text { Hypersensitivity } \\
\text { reactions }\end{array}$ & 7 & 12,855 & $0.05(0.02-0.10)$ \\
\hline & Subtotal & 8 & 12,855 & $0.06(0.02-0.11)$ \\
\hline
\end{tabular}

AEIs adverse events of interest, EMA European Medicines Agency

recorded in children. There were differences in the number of orange cards recorded by practices, but this did not seem to be impacted by practice denominator or number of patients vaccinated. Further, there was no clear pattern in the AEIs across weeks 37-41; AEIs increase from weeks 37 to 79 , decrease at week 40, and then increase again. The most commonly reported AEIs were respiratory, musculoskeletal and neurological symptoms (Table 6). Sensitivity and anaphylaxis were the least frequently recorded AEIs. For data related to GSK vaccines where both surveillance systems were assessed, a higher rate of AEIs was recorded using the enhanced passive surveillance over the standard surveillance by practices in the RCGP RSC sentinel network. Whilst the pattern of reported AEIs was similar in both surveillance systems, all but two AEI categories were recorded more often in practices participating in the enhanced passive surveillance and thus using ADR cards.
It is likely that ADR card use stimulated more ADR recording.

\section{Limitations}

As this was an interim study, when the results were collected we did not know if all the cards had been collected or counted, so there may be some missing data. As compared to routine pharmacovigilance systems or purely passive surveillance, our approach may have stimulated reporting of AEIs, further research is needed to test this hypothesis. Similarly, less AEIs may have been reported on the orange cards because we did not take into account health literacy of our patients; however, given the fact that the orange cards were written in plain English and the large number of patients vaccinated, any effects of health literacy are likely to be minimal. We were unable to formally compare AEI 
Table 7 AEI rates reported via any method for 2016 ten orange card practices and RCGP RSC network 2016 (weeks $37-41)$

\begin{tabular}{|c|c|c|c|c|}
\hline $\begin{array}{l}\text { AEI category } \\
\text { using ontological } \\
\text { classification }\end{array}$ & $\begin{array}{l}\text { Vaccine } \\
\text { brand }\end{array}$ & $\begin{array}{l}\text { AEI rate for orange card practices } \\
\text { weeks } 37-41(95 \% \mathrm{CI}) 7 \text { days } \\
\text { post-vaccination }(\%)\end{array}$ & $\begin{array}{l}\text { AEI rate for RCGP RSC weeks } \\
37-41 \text { ( } 95 \% \text { CI) } 7 \text { days post- } \\
\text { vaccination (excluding pilot) (\%) }\end{array}$ & $\begin{array}{l}\text { Pearson } \\
\text { chi- } \\
\text { square } \\
(p)\end{array}$ \\
\hline \multirow[t]{2}{*}{ All AEI } & \multirow[t]{2}{*}{ GSK } & 6.88 & 3.30 & \multirow[t]{2}{*}{$<0.0001$} \\
\hline & & $6.35-7.42$ & $2.68-3.96$ & \\
\hline \multirow[t]{2}{*}{ Respiratory } & \multirow[t]{2}{*}{ GSK } & 3.31 & 1.12 & \multirow[t]{2}{*}{$<0.0001$} \\
\hline & & $2.94-3.69$ & $0.76-1.52$ & \\
\hline \multirow[t]{2}{*}{ Musculoskeletal } & \multirow[t]{2}{*}{ GSK } & 2.16 & 0.46 & \multirow[t]{2}{*}{$<0.0001$} \\
\hline & & $1.86-2.47$ & $0.23-0.73$ & \\
\hline \multirow[t]{2}{*}{ Neurological } & \multirow[t]{2}{*}{ GSK } & 1.34 & 0.23 & \multirow[t]{2}{*}{$<0.0001$} \\
\hline & & $1.10-1.58$ & $0.07-0.43$ & \\
\hline \multirow[t]{2}{*}{ General symptoms } & \multirow[t]{2}{*}{ GSK } & 1.20 & 0.13 & \multirow[t]{2}{*}{$<0.0001$} \\
\hline & & $0.98-1.43$ & $0.03-0.26$ & \\
\hline \multirow[t]{2}{*}{ Gastrointestinal } & \multirow[t]{2}{*}{ GSK } & 1.06 & 0.07 & \multirow[t]{2}{*}{$<0.0001$} \\
\hline & & $0.85-1.28$ & $0.00-0.17$ & \\
\hline \multirow[t]{2}{*}{ Local symptoms } & \multirow[t]{2}{*}{ GSK } & 0.77 & 0.00 & \multirow[t]{2}{*}{$<0.0001$} \\
\hline & & $0.59-0.95$ & NA & \\
\hline \multirow[t]{2}{*}{ Fever/pyrexia } & \multirow[t]{2}{*}{ GSK } & 0.69 & 0.96 & \multirow[t]{2}{*}{0.136} \\
\hline & & $0.51-0.86$ & $0.63-1.32$ & \\
\hline \multirow[t]{2}{*}{ Rash } & \multirow[t]{2}{*}{ GSK } & 0.34 & 0.50 & \multirow[t]{2}{*}{0.221} \\
\hline & & $0.22-0.46$ & $0.26-0.76$ & \\
\hline \multirow{2}{*}{$\begin{array}{l}\text { Sensitivity/ } \\
\text { anaphylaxis }\end{array}$} & \multirow[t]{2}{*}{ GSK } & 0.08 & 0.00 & \multirow[t]{2}{*}{$\mathrm{NA}$} \\
\hline & & $0.02-0.15$ & NA & \\
\hline
\end{tabular}

$A E I$ adverse event of interest, $C I$ confidence interval

rates with information reported in the GSK's Fluarix Tetra clinical trials and summarised in the summary of product characteristics (SmPc); the categorisation of these data does not perfectly match those used in this study. However, for the common items, the reported rates from this enhanced study were systematically below the rates reported in the Fluarix Tetra SmPc. The fact that we did not record returned ADR indicating that no AEI had occurred is a limitation of this study and should be addressed in future surveillance of this type. There is also a need to understand better about the low rate of AEI recording in children and young adults under 18 years, even though there were low numbers of individuals in this age group.

\section{Interpretation}

We did not detect any safety signal that would have required further investigation between weeks 37 and 41. 
Our interpretation is that customised ADR cards with predefined fields are an efficient way to stimulate the AEI reporting, including for local reactions, compared to standard surveillance of records.

In the future, some adjustment to enhanced safety surveillance might be necessary. Investigations are needed to further improve the return rate of orange cards and extend the use of this methodology to a wider population, inclusive of children receiving nasal influenza vaccine, which is part of the UK's vaccination policy (this study was undertaken to satisfy EMA requirement for the marketing authorisation holder that sponsored this study) [32].

\section{Generalisability}

The level of detection of AEIs in our pilot study is comparable to that found in other observation systems $[33,34]$. This seems to suggest that use of ADR cards together with EHR system weekly data extractions is an appropriate tool for adverse event surveillance. Other approaches have been proposed to meet EMA requirements [35].

\section{CONCLUSIONS}

This study demonstrated feasibility of conducting enhanced active surveillance per EMA recommendations. The use of a customised ADR card led to a doubling of AEIs reports over passive surveillance in adults. This study delivers meaningful results and could be used as a mechanism for meeting the requirements set out for safety surveillance.

\section{ACKNOWLEDGEMENTS}

Fluarix Tetra is a trade mark of the GSK group of companies.

We would like to thank the patients of the participating practices for allowing their data to be used for surveillance and research and for taking the time to complete the ADR cards. In addition, we thank Apollo Medical Systems for managing secure data extraction. We thank Florence Lair and Karen Stuttard from GSK for their contribution to this study; RCGP RSC for provision of aggregated comparator data. Finally, we would like to thank Ana Correa for her major contribution to this work while Primary Care Scientist for RCGP RSC at University of Surrey.

Funding. GlaxoSmithKline Biologicals SA (Grant no. EPI FLU-046 VS UK), Wavre, Belgium was the funding source and was involved in study design and interpretation. GlaxoSmithKline Biologicals SA, Wavre, Belgium also funded the article processing charges and open access fee. All authors had full access to all of the data in this study and take complete responsibility for the integrity of the data and accuracy of the data analysis.

Authorship. All named authors meet the International Committee of Medical Journal Editors (ICMJE) criteria for authorship for this article, take responsibility for the integrity of the work as a whole, and have given their approval for this version to be published.

Disclosures. Gaël Dos Santos reports he was employed by Business \& Decision Life Sciences on behalf of GSK at the time of the study and is now employed by the GSK group of companies. Gaël Dos Santos is an employee of the GSK group of companies. Gaël Dos Santos holds shares in the GSK group of companies as part of their employee remuneration. Anne Schuind is an employee of the GSK group of companies. Anne Schuind holds shares in the GSK group of companies as part of their employee remuneration. Silvia Damaso is an employee of the GSK group of companies. Vishvesh Shende reports he is a consultant for VPN Consultancy Ltd, London UK (on Behalf of GSK). Simon de Lusignan reports that he will receive an honorarium from Seqirus for attending a global influenza advisory board and that he and his team have collaborated with the funder (GSK) before within the IMIfunded projects ADVANCE and DRIVE. Simon de Lusignan also reports personal fees from Seqirus, during the conduct of the study; and 
other funding from GlaxoSmithKline Biologicals SA, Wavre, Belgium, outside the submitted work. Rachel Byford, Filipa Ferreira, Ivelina Yonova and Christopher McGee have nothing to disclose.

Compliance with Ethics Guidelines. Ethics committee approval was obtained in England from the Health Research Authority (IRAS project ID 211560). GlaxoSmithKline Biologicals SA, Wavre, Belgium funded the project and was involved in study design and interpretation. This study received a favourable ethics committee approval: Integrated Research Application System (IRAS) project ID 211560; Research Ethics Committee (REC) reference 16/NE/0271. All procedures performed in studies involving human participants were in accordance with the ethical standards of the institutional and/or national research committee and with the 1964 Helsinki declaration and its later amendments or comparable ethical standards. Informed consent was obtained from all individual participants included in the study.

Data Availability. The datasets generated during and/or analysed during the current study are not publicly available due data governance constraints under the Data Protection Act 1998, United Kingdom Parliament but are available from the corresponding author on reasonable request or through the standard process of application of the RCGP Research and Surveillance Centre (http://www.rcgp.org. uk/clinical-and-research/our-programmes/ research-and-surveillance-centre.aspx) or by contacting Ivelina Yonova, i.yonova@surrey.ac.uk.

Open Access. This article is distributed under the terms of the Creative Commons Attribution-NonCommercial 4.0 International License (http://creativecommons.org/licenses/ by-nc/4.0/), which permits any noncommercial use, distribution, and reproduction in any medium, provided you give appropriate credit to the original author(s) and the source, provide a link to the Creative Commons license, and indicate if changes were made.

\section{REFERENCES}

1. European Medicines Agency (EMA) Pharmacovigilance Risk Assessment Committee (PRAC). Interim guidance on enhanced safety surveillance for seasonal influenza vaccines in the EU. London, EMA: Ref: EMA/PRAC/222346/2014; 10 April 2014. http://www.ema.europa.eu/docs/en_GB/document library/Scientific_guideline/2014/04/WC500165492. pdf. Accessed 4 Sept 2017.

2. European Medicines Agency (EMA). Guideline on influenza vaccines non-clinical and clinical module. 2016. EMA/CHMP/VWP/457259/2014 Committee for Medicinal Products for Human Use. http://www.ema.europa.eu/docs/en_GB/document_ library/Scientific_guideline/2016/07/WC500211324. pdf. Accessed 4 Sept 2017.

3. European Medicines Agency (EMA). Explanatory note on the withdrawal of the note for guidance on harmonization of requirements for influenza vaccines and of the core SmPC/PL for inactivated seasonal influenza vaccines. London: EMA; 2014. Contract no.: EMA/CHMP/VWP/40560/2014. http://www.ema.europa.eu/ema/index.jsp?curl= pages/includes/document/document_detail.jsp?web ContentId=WC500161022\&mid=WC0b01ac05800 9a3dc.

4. Lee GM, Greene SK, Weintraub ES, et al. H1N1 and seasonal influenza vaccine safety in the vaccine safety datalink project. Am J Prev Med. 2011;41(2):121-8. $\quad$ https://doi.org/10.1016/j. amepre.2011.04.004.

5. Gao D, Yang H, Deng B, et al. Safety and immunogenicity of three seasonal trivalent influenza vaccines in the Chinese military. Hum Vaccin Immunother. 2016;12(10):2634-9. https://doi.org/ 10.1080/21645515.2016.1194147.

6. Bettinger JA, Vanderkooi OG, MacDonald J, Kellner JD. Rapid online identification of adverse events after influenza immunization in children by PCIRN's National Ambulatory Network. Pediatr Infect Dis J. 2014;33(10):1060-4. https://doi.org/10. 1097/INF.0000000000000373.

7. Folkenberg M, Callréus T, Svanström H, ValentinerBranth P, Hviid A. Spontaneous reporting of adverse events following immunisation against pandemic influenza in Denmark November 2009-March 2010. Vaccine. 2011;29(6):1180-4.

8. de Lusignan S, Hague N, van Vlymen J, Kumarapeli P. Routinely-collected general practice data are complex, but with systematic processing can be used for quality improvement and research. Inform Prim Care. 2006;14(1):59-66. 
9. de Lusignan S, van Weel C. The use of routinely collected computer data for research in primary care: opportunities and challenges. Fam Pract. 2006;23(2):253-63.

10. de Lusignan S. Codes, classifications, terminologies and nomenclatures: definition, development and application in practice. Inform Prim Care. 2005;13(1):65-70.

11. Department of Health. Determining arrangements for supporting research in primary and community care. January 2013. http://webarchive.nationalarchi ves.gov.uk/20130107105354/http://www.dh.gov.uk/ health/files/2012/12/Determining-arrangements-forsupporting-research-in-primary-and-communitycare-updated-January-2013.pdf.

12. de Lusignan S, Dos-Santos G, Correa A, et al. Postauthorisation passive enhanced safety surveillance of seasonal influenza vaccines: protocol of a pilot study in England. BMJ Open. 2017;7(5):e015469. https://doi.org/10.1136/bmjopen-2016-015469.

13. Correa A, Hinton W, McGovern A, et al. Cohort profile: royal College of General Practitioners Research and Surveillance Centre (RCGP RSC) sentinel network. BMJ Open. 2016;6:e011092. https:// doi.org/10.1136/bmjopen-2016-011092.

14. Avery AJ, Anderson C, Bond CM, et al. Evaluation of patient reporting of adverse drug reactions to the UK 'Yellow Card Scheme': literature review, descriptive and qualitative analyses, and questionnaire surveys. Health Technol Assess. 2011;15(20):1-234, iii-iv. https://doi.org/10.3310/ hta15200.

15. Public Health England, Department of Health, NHS England. Flu plan winter 2016/17. 2016. PHE publications gateway number: 2016027. https://www. gov.uk/government/uploads/system/uploads/ attachment_data/file/525967/Annual_flu_plan_ 2016_to_2017.pdf. Accessed 4 Sept 2017.

16. NHS England (2015). Enhanced Service Specification Seasonal influenza and pneumococcal polysaccharide vaccination programme 2015/16. https://www.england.nhs.uk/commissioning/wpcon tent/uploads/sites/12/2015/09/seasnl-flu-pneumoco ccal-upd.pdf. Accessed 4 Sept 2017.

17. de Lusignan S, Correa A, Ellis J, Pebody R. Influenza vaccination: in the UK and across Europe. Br J Gen Pract. 2016;66(650):452-3. https://doi.org/10.3399/ bjgp16X686677.

18. Martin Arias LH, Sanz R, Sainz M, Treceno C, Carvajal A. Guillain-Barre syndrome and influenza vaccines: a meta-analysis. Vaccine. 2015;33(31): 3773-8. https://doi.org/10.1016/j.vaccine.2015.05. 013.
19. Szakacs A, Darin N, Hallbook T. Increased childhood incidence of narcolepsy in western Sweden after H1N1 influenza vaccination. Neurology. 2013;80(14):1315-21. https://doi.org/10.1212/wnl. 0b013e31828ab26f.

20. Pulse News Article. http://www.pulsetoday.co.uk/ your-practice/practice-topics/it/nhs-overriding700000-patient-opt-outs-to-gp-data-being-shared/ 20009761.fullarticle. Accessed 4 Sept 2017.

21. de Lusignan S. Codes, classifications, terminologies and nomenclatures: definition, development and application in practice. Inform Prim Care. 2005;13(1):65-70.

22. de Lusignan S. In this issue: ontologies a key concept in informatics and key for open definitions of cases, exposures, and outcome measures. J Innov Health Inform. 2015;22(2):170. https://doi.org/10. 14236/jhi.v22i2.170.

23. Liyanage $\mathrm{H}$, Krause $\mathrm{P}$, de Lusignan $\mathrm{S}$. Using ontologies to improve semantic interoperability in health data. J Innov Health Inform. 2015;22(2):309-15. https://doi.org/10.14236/jhi. v22i2.159.

24. Public Health England. Vaccine uptake guidance and the latest coverage data. https://www.gov.uk/ government/collections/vaccine-uptake\#seasonalflu-vaccine-uptake. Accessed 4 Sept 2017.

25. Harcourt S, Morbey RA, Bates C, et al. Estimating primary care attendance rates for fever in infants after meningococcal B vaccination in England using national syndromic surveillance data. Vaccine. 2018;36(4):565-71. https://doi.org/10.1016/j. vaccine.2017.11.076.

26. de Lusignan S, Correa A, Smith GE, et al. RCGP Research and Surveillance Centre: 50 years' surveillance of influenza, infections, and respiratory conditions. $\mathrm{Br} \mathrm{J}$ Gen Pract. 2017;67(663):440-1. https://doi.org/10.3399/ bjgp17X692645.

27. Pathirannehelage S, Kumarapeli $\mathrm{P}$, Byford R, Yonova I, Ferreira F, de Lusignan S. Uptake of a dashboard designed to give realtime feedback to a sentinel network about key data required for influenza vaccine effectiveness studies. Stud Health Technol Inform. 2018;247:161-5.

28. de Lusignan S, Stephens PN, Adal N, Majeed A. Does feedback improve the quality of computerized medical records in primary care? J Am Med Inform Assoc. 2002;9(4):395-401.

29. Scholz F. Confidence bounds and intervals for parameters relating to the binomial negative binomial Poisson and hypergeometric distributions with 
applications to rare events. 2008. http://www.stat. washington.edu/fritz/DATAFILES498B2008/Confid enceBounds.pdf. Accessed 4 Sept 2017.

30. Office for National Statistics. Population estimates for UK, England and Wales, Scotland and Northern Ireland: mid-2016. https://www.ons.gov.uk/people populationandcommunity/populationandmigration/ populationestimates/bulletins/annualmidyearpopula tionestimates/latest. Accessed 4 Sept 2017.

31. Lauer SA, Kleinman KP, Reich NG. The effect of cluster size variability on statistical power in cluster-randomized trials. PLoS One. 2015;10(4): e0119074. https://doi.org/10.1371/journal.pone. 0119074 .

32. Pebody RG, Green HK, Andrews N, et al. Uptake and impact of vaccinating school age children against influenza during a season with circulation of drifted influenza A and B strains, England, 2014/15. Euro Surveill. 2015;20(39):1-11. https:// doi.org/10.2807/1560-7917.es.2015.20.39.30029.

33. Bardenheier BH, Duderstadt SK, Engler RJ, McNeil MM. Adverse events following pandemic influenza
A (H1N1) 2009 monovalent and seasonal influenza vaccinations during the 2009-2010 season in the active component U.S. military and civilians aged 17-44 years reported to the Vaccine Adverse Event Reporting System. Vaccine. 2016;34(37):4406-14. https://doi.org/10.1016/j.vaccine.2016.07.019.

34. Haber P, Moro PL, Lewis P, Woo EJ, Jankosky C, Cano M. Post-licensure surveillance of quadrivalent inactivated influenza (IIV4) vaccine in the United States, Vaccine Adverse Event Reporting System (VAERS), July 1, 2013-May 31, 2015. Vaccine. 2016;34(22):2507-12. https://doi.org/10.1016/j. vaccine.2016.03.048.

35. Demeulemeester M, Lavis N, Balthazar Y, Lechien P, Heijmans S. Rapid safety assessment of a seasonal intradermal trivalent influenza vaccine. Hum Vaccin Immunother. 2017;13(4):889-94. https://doi. org/10.1080/21645515.2016.1253644.

36. Chief Medical Officer. Annual flu plan 2016 to 2017. London; Department of Health, 2016. Page 41. https://www.gov.uk/government/uploads/system/ uploads/attachment_data/file/525967/Annual_flu_ plan_2016_to_2017.pdf. Accessed 4 Sept 2017. 